\title{
KARLA Katalogportal der UB Kassel lưu trữ sách mới của ISR
}

\author{
Nguyễn Thanh Thanh Huyền \\ Trung tâm ISR \\ Trường Đại học Phenikaa \\ Ngày 13 tháng 8 năm 2021
}

Cuốn sách chuyên khảo monograph có tiêu đề $A$ mindsponge-based investigation into the psychoreligious mechanism behind suicide attacks của 3 tác giả Vương Quân Hoàng, Nguyễn Minh Hoàng và Lê Tâm Trí, thuộc Trung tâm ISR (ĐH Phenikaa), được xuất bản chính thức ngày 2/8/2021.

Cuốn sách do nhà xuất bản De Gruyter (Sciendo Imprint, Poland) phát hành, với mã số ISBN: 9788366675582 (bìa mềm). Độc giả đã có thể đặt sách qua hệ thống Amazon, trong đó Amazon Pháp (https://www.amazon.fr/dp/8366675580/) và Amazon Đức (https://www.amazon.de/dp/8366675580/) đã có thể sẵn sàng giao sách (tức có sẵn trong kho).

Chỉ khoảng hơn một tuần sau khi chính thức phát hành, đã có ĐH Kassel yết lên danh sách tài liệu trong thư viện đầu tiên nối với hệ thống OCLC. Có thể truy cập bản ghi thông tin ấn phẩm qua địa chỉ: https://hds.hebis.de/ubks/Record/HEB484063863

An allen Standorten der Universitäts bibliothek wird ein eingeschränkter Benutzungs betrieb angeboten. Weitere Informationen finden Sie unter www.uni-kassel.de/ub/

\section{Bibliothek}

KARLA Katalogportal der UB Kassel

Anmelden

A Mindsponge-Based Investigation into the PsychoReligious Mechanism Behind Suicide Attacks

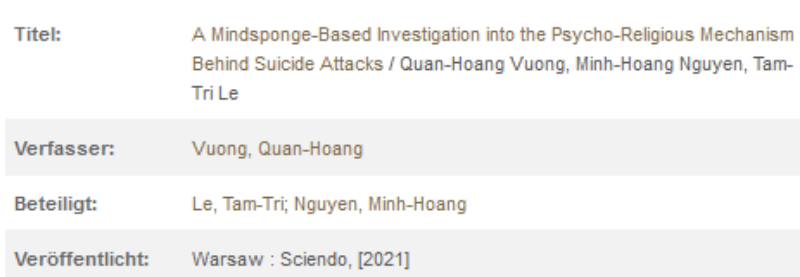

Universitätsbibliothek Kassel, Landesbibliothek und Murhardsche Bibliothek der Stadt Kassel. Kassel, 34127 Germany. 
Sciendo Imprint là dòng ấn phẩm của De Gruyter (tổ hợp xuất bản Đức đã hoạt động gần 300 năm). Sciendo có tên trước đây là De Gruyter Open, trụ sở tại Warsaw, Poland.

Với tốc độ nhập sách lưu trữ rất nhanh như trên, ISR có niềm tin rằng trong tương lai gần, sẽ có thêm nhiều thư viện quốc tế lưu trữ ấn phẩm mới này, góp phần lan tỏa kết quả công việc nghiên cứu của Trung tâm trong cộng đồng độc giả thế giới.

Cuốn monograph vừa hoàn thành phản ánh tinh thần đầu tư hiệu quả nguồn lực hạn chế, tập trung vào chất lượng công việc, thay cho khối lượng dữ liệu hoặc số lượng trang bản thảo, dựa trên nguyên lý phát biểu trong bài "The (ir)rational consideration of the cost of science in transition economies";

https://www.nature.com/articles/s41562-017-0281-4. 